\title{
ANALISE DO RELATÓRIO DE AVALIAÇÃO PSICOLÓGICA DA CLIENTELA DE CLASSE ESPECIAL PARA DEFICIENTE MENTAL.
}

\author{
Alice Ivone Marconi (*) \\ Sônia Santa Vitaliano Graminha (**)
}

\section{RESUMO}

Os dados contidos nos Relatórios de Avaliação Psicológica dos alunos que freqüentam classe especial para deficiente mental foram analisados neste trabalho, tomando-se por base o modelo proposto na Instrução DAE $\backslash S E$, publicada no Diário Oficial do Estado de São Paulo (1986), sendo acrescentadas outras análises do interesse dos pesquisadores. Verificou-se a existência de Relatório para cêrca de $79 \%$ dos alunos e a análise dos dados mostrou a ausência de um padrão consensual entre os psicólogos para a realização da avaliação e apresentação dos resultados e o uso de técnicas e testes variados com emprego mais freqüente dos testes de nível intelectual. Dentre os Relatórios analisados, alguns apresentam valores de QI (25\%) e grande parte deles não contém qualquer indicação quanto ao tipo de classe que a criança deverá freqüentar (38\%) e nem qualquer orientação ao professor visando auxiliá-lo no seu trabalho junto à criança (47\%).

\section{1 - INTRODUÇÃO}

A forma pela qual as crianças têm sido efetivamente identificadas como clientes de classe especial apresenta sérios problemas (Isnard e colaboradores, 1977). A avaliação psicológica enquanto critério legal para colocação da criança em classe especial para deficiente mental (CEDM) suscita questões acerca da forma como a avaliação é feita, qual a sua função na vida escolar da criança ou em que ela pode contribuir em termos educacionais e até mesmo quanto ao fato de estar sendo realmente cumprida essa exigência legal.

Paschoalick (1981) verificou que, no contexto onde foi realizado seu trabalho, $61,40 \%$ das crianças foram matriculadas nas CEDM sem a avaliação psicológica devido a inexistência de psicólogos.

Como observam Matuszek e Oakland (1979), o papel do psicólogo enquanto responsável em determinar a elegibilidade das crianças para CEDM é percebido primariamente, se não exclusivamente, na administração e interpretação de testes. Muitos autores têm criticado os testes formais padronizados usados no diagnóstico, alegando que o fato de serem culturamente viesados podem comprometer a decisão da colocação das crianças em programas

(*) Psicóloga junto à Clínica Higienópolis - Ribeirăo Preto - SP

USP Professora Assistente Doutora junto ao Departamento de Psicologia e Educaçăo da FFCLRP -

Paidéia, FFCLRP - USP, Rib. Preto, 3, Ago/Jan, 1993. 
especiais. Verifica-se que os escores de inteligência (QI) são freqüentemente considerados quando se vai fazer decisōes educacionais mesmo que os testes de QI possam não refletir as dimensões críticas a serem consideradas quando se julga a prontidão do aluno (Matuszek e Oakland, 1979 ; Palmer, 1980; Fields e Kumar, 1982 e Schneider e Byrne, 1984). Nesse sentido surgem problemas quando as informações sobre a fidedignidade e validade baseados em escores de grandes grupos são usadas de forma inadequada para se efetuar decisōes educacionais para um aluno individualmente (Palmer. 1980).

Embora seja criticada a atuação do psicólogo como avaliador, decorrente da utilização de testes, o próprio dispositivo legal parece suscitar a utilização de instrumentos desse tipo, quando dispōe que o atendimento educacional em CEDM é reservado aos portadores de deficiência mental de grau leve (Inciso III do artigo $3^{\circ}$ da Resolução 247 \86).

As contradições $e$, por conseguinte, as questões que têm sido levantadas acerca da utilização dos resultados dos testes de inteligência, e especialmente as dúvidas acêrca de como estes dados poderão auxiliar o professor no planejamento de intervençōes educacionais, têm gerado grande preocupação e interesse em discutir e pesquisar o assunto. Essa preocupação passa a ter um significado ainda maior quando se verifica que os professores freqüentemente expressam desprazer com a qualidade e importância dos relatos, com a insuficiência das técni as de coleta de dados utilizadas pelos psicólogos e com a exiguidade de informações relevantes para intervir junto à criança (Matuszek e Oakland, 1979).

Entretanto, parece estar sendo reconhecida a importância de se considerar outras variáveis que não exclusivamente os resultados de testes, quando se faz decisões para colocação em classes especiais tais como o comportamento observando em sala de aula e a avaliação da linguagem receptiva e expressiva (Knoff, 1983).

Quanto ao aspecto da redação da avaliação, Bagnato (1980) alega que as dificuldades dizem respeito não apenas e necessariamente à natureza da informação coletada, mas podem estar relacionadas com a síntese, organização, fomato e estilo de comunicação dos dados. Relata também que os professores e pais tendem a ver o diagnóstico dos relatórios mais positivamente quando eles são escritos de forma clara, em termos comportamentais sugerindo objetivos imediatos para o planejamento de currículo.

O questionamento a respeito da validade ou da contribuiçāo da avaliação psicológica para se tomar decisões educacionais acerca dos alunos tem levado muitos autores a chamar atenção para os riscos que se pode correr quando o processo de decisão é baseado inteiramente na avaliação do psicólogo. Nesse sentido não se pode deixar de ressaltar o problema da não participação de professores especializados. E sugerido pela literatura (Denari, 1984) que o professor de classe especial tende a aceitar os procedimentos e atitudes pré-estabelecidos, cabendo-lhe a função de finalizar o processo de 
encaminhamento e posteriormente de trabalhar com os alunos procurando solucionar os problemas apresentados por outros profissionais. Parece que nāo é dada ao professor especializado a oportunidade de avaliar a criança segundo as habilidades que sua formação permite, a fim de que possa formular suas hipóteses e intervir tanto no sentido de indicar a criança para classe especial quanto de fazer planejamento de ensino baseado no conhecimento da criança, a partir de suas técnicas ou recursos pedagógicos.

As afirmações acima parecem ser confirmadas na medida em que pode ser observado o quanto os psicólogos têm sido responsabilizados pela efetivação da matrícula em CEDM. E através dos dados fornecidos pelos psicólogos que os professores especializados visualizam a possibilidade de conhecer melhor a criança e a partir daí poder intervir junto a cada uma. Entretanto, Paschoalick (1981) nota que o professor especializado não é orientado para fazer uma análise cuidadosa dos resultados de um laudo psicológico e chama a atenção para o fato de que se os resultados foram fornecidos por um psicólogo, estes parecem legítimos e irrefutáveis para os professores. Essa autora, analisando laudos psicológicos, constatou não existir um padrão consensual de avaliação e que independentemente da análise dos instrumentos utilizados na avaliação psicológica, as informaçōes fornecidas nos laudos são insuficientes para subsidiar um plano de intervenção educacional especializado. Ela afirma serem as informações fornecidas genéricas e que poderiam equivaler àquelas fornecidas pelos professores regulares. Aponta ainda a alienação da família no processo de encaminhamento da criança.

Holland (1980) chama atenção para a importância de uma comunicação mais efetiva entre os profissionais no sentido de garantir o sucesso da avaliaçāo e do processo de encaminhamento.

Denari (1984) acrescenta que a forma de avaliar o aluno encaminhado à classe especial está ligado às preferências ou peculiaridades da formaçāo de cada profissional, ou ainda, à instituição à qual se encontra vinculado. É sugerido pela autora a importância da definição do papel dos vários agentes envolvidos no processo de encaminhar alunos para os serviços de educação especial.

A tomada de decisão sobre o encaminhamento de um aluno deve ser feita com muita cautela e mediante a comprovação total de que este é incapaz de acompanhar um programa de classe regular e após ter-se colocado à disposição do aluno o máximo de oportunidades de aprendizagem.

Diante das inúmeras questões que têm sido levantadas, acerca da avaliação psicológica como critério para colocação da criança em CEDM, depreende-se a importância dos estudos que possam contribuir, de alguma forma, para o fornecimento de dados e direções mais evidentes. E nesse sentido que o presente trabalho foi planejado objetivando a investigação dos conteúdos dos Relatórios de Avaliação Psicológica das crianças que freqüêntam CEDM da cidade de Ribeirão Preto, identificando as técnicas e instrumentos de avaliação

Paidéia, FFCLRP - USP, Rib. Preto, 3, Ago/Jan, 1993. 
utilizados e os resultados encontrados, os motivos do encaminhamento da criança, os exames já realizados por outros profissionais e as proposiçōes de tratamento, a indicação quanto a classe que a criança deve freqüentar $e$ as orientaçöes para o trabalho do professor junto ao aluno.

\section{2 - METODO}

Os dados deste trabalho foram extraídos de 63 Relatórios de Avaliação Psicológica de alunos freqüentando seis CEDM da Rede Oficial de Ensino de Ribeirão Preto - SP. A consulta aos Relatórios foi efetuada no período de março a junho de 1987, mediante autorizaçāo dos diretores das escolas, tendo sido transcritos integralmente pelos pesquisadores na própria escola, numa sala que garantia a privacidade de trabalho com esse material.

A análise desses Relatórios foi efetuada tomando-se por base determinadas informaçōes que eles devem conter, de acordo com o modelo proposto na Instrução DAE \SE publicada no Diário Oficial do Estado de São Paulo (1986), sendo acrescentadas também outras análises do interesse dos pesquisadores.

Tendo-se definido o que analisar procedeu-se leitura dos Relatórios e as informações pretendidas foram selecionadas e anotadas em protocolos de registros especiais. A partir desses protocolos os dados foram tabulados e calculadas as respectivas porcentagens ou foram submetidos a uma análise qualitativa.

\section{3 - RESULTADOS}

Inicialmente foi calculada a porcentagem de alunos de CEDM que possui Relatório de Avaliação Psicológica e constatou-se que, das 80 crianças que frequentam CEDM, 78,75\% possuem Relatório de Avaliação Psicológica. Dentre as 6 CEDM, somente em 2, todos os alunos têm o Relatório.

Em seguida foram efetuadas as análises dos Relatórios de Avaliação Psicológica visando verificar em que proporção eles contém informaçōes relativas aos vários aspéctos mencionados a seguir e qual o conteúdo dessas informaçōes: a) Técnicas e instrumentos utilizados na avaliação psicologica das crianças: tipo e nome dos testes; b) Resultados referentes à avaliação intelectual: Quociente de Inteligência (QI) e \ou Idade Mental (IM) dos alunos avaliados;

c) Resultados referentes à avaliação psicomotora; d) Resultados referentes à avaliação de personalidade; e) Exames já realizados por outros profissionais e proposiçōes de tratamento; f) Motivos do encaminhamento da criança para CEDM; g) Indicação quanto à classe que a criança deve freqüentar.

Os resultados encontram-se nas tabelas e quadro subsequentes. As letras utilizadas nas tabelas 1 e 2 correspondem as primeiras letras que compõem o nome de cada instrumento ou técnica e estão especificadas a seguir: 
TNI $=$ Teste de nível intelectual

$\mathbf{E P}=$ Entrevista com a professora

TPA = Teste de prontidão para analfabetizaçāo

TMPM = Teste de maturidade Percepto-motora

TP $=$ Teste de Personalidade

APP $=$ Avaliação Psicopedagógica

OCC = Observação Clínica da criança

ARHB = Avaliação do Repertório de Habilidades Básicas

$\mathbf{E M}=$ Entrevista com a mäe

TPV = Teste de Percepção Visual

EMS = Escala de Maturidade Social

ADL = Avaliação do Desenvolvimento da Linguagem

Conjunto de Técnicas e Instrumentos de Avaliação Utilizados

TNI

EP

TNI, TPA

TNI, TMPM

TNI, TP

OCC, EM

TNI, TPA, APP

TNI, TPA, TMPM

TNI, TPA, OCC

TNI, TMPM, APP

TNI, TMPM, TP

TMPM, ARHB, EM

TNI, ARHB, EMS

TNI, OCC, EM

TNI, TPA, ARHB

TMP, ARHB, ADL

TNI, TMPM, OCC

TNI, TPA, TMPM, APP

TNI, TPA, TMPM, ARHB

TNI, TPA, ARHB, TPV

TNI, TMPM, OCC, EM, EP

TNI, TMPM, APP, OCC, TPV

Total de Relatórios com especificação

dos instrumentos e técnicas de

avaliação

Total de Relatórios sem especificação

dos instrumentos e técnicas de

Avaliação. f

$\%$

7,94

1,58

7,94

6,36

1,58

3,19

1,58

7,94

1,58

6,36

11,14

1,58

1,58

1,58

1,58

1,58

1,58

17,46

3,19

1,58

1,58

1,58

92,06

$\frac{1}{58}$

5

7,94

TABELA 1 = Freqüência ( $($ ) e porcentagem $(\%)$ de Relătórios que çitam cada conjunto de técnicas e instrumentos ufilizados na avaliação da criança que frequéta CEDM

Paidéia, FFCLRP - USP, Rib. Preto, 3, Ago/Jan, 1993. 
Observa-se que $92,06 \%$ dos Relatórios especificam os instrumentos ou técnicas utilizadas na avaliaçāo psicológica, sendo que estes aparecem em número variado (de um a cinco) e combinados em 22 conjuntos diferentes. Dentre as várias combinaçōes, a mais frequente (aparecendo em 17,46\% dos Relatórios) se constitue de teste de nível intelectual, teste de prontidão para alfabetização, teste de maturidade percepto-motora e avaliação psicopedagógica, seguida (em 11,14\% dos Relatórios) da combinação: teste de nível intelectual, de maturidade percepto motora e de personalidade. As outras combinações ou a utilização de um único instrumento aparecem em porcentagens variando de 1.58 a $7.94 \%$.

\begin{tabular}{|lcc|}
\hline $\begin{array}{l}\text { Técnicas e Instrumentos de Avaliação } \\
\text { mencionados nos Relatórios. }\end{array}$ & f & $\%$ \\
\hline & & \\
TNI & 53 & 84,12 \\
TPA & 27 & 42,85 \\
TMPM & 37 & 58,73 \\
APP & 17 & 26,98 \\
TP & 8 & 12,69 \\
OCC & 7 & 11,14 \\
ARH & 7 & 11,14 \\
EM & 5 & 7,94 \\
TPV & 2 & 3,17 \\
EMS & 1 & 1,58 \\
EP & 2 & 3,17 \\
ADL & 1 & 1,58 \\
Técnicas e instrumentos não & 5 & 7,94 \\
especificados. & & \\
\hline
\end{tabular}

TABELA 2 - Técnicas e instrumentos de avaliação das crianças que freqüentam CEDM citados nos Relatórios. Frequência (f) e porcentagem (\%).

A tabela 2 mostra que os Relatórios citam 12 tipos de instrumentos ou técnicas diferentes sendo os mais frequentes os testes de nível intelectual $(84,12 \%)$ seguidos do teste de maturidade percepto motora $(58,73)$, do teste de prontidâo para analfabetização $(\mathbf{4 2 , 8 5 \% )}$ e da avaliação psicopedagógica (26,98\%). As outras técnicas ou instrumentos aparecem numa porcentagem mais baixa variando de 1,58 à $12,69 \%$.

Na tabela 3 estão relacionados os testes cujos nomes foram mencionados nos Relatórios e a freqüência com que cada um aparece. 
Wescheler Intelligence

Scale for Children-WISC

Escala de Inteligência

Stanford Binet Terman

Testes de Nível Intelectual

Merrill

Teste da Figura Humana de Goodenough 6

Escala de maturidade

Mental-Columbia

Escala Raven Especial

Teste Metropolitano de Prontidão - TMP 5

APPI (DAE) 1

Testes de Prontidão

Teste de Prontidão para

para Alfabetização

Leitura de Eloah Ribeiro

Kunz

Testes de Personalidade

HTP

2

Escala de Maturidade Escala de Maturidade Social de Vineland Social

Testes de Maturidade Teste Guestáltico Visomotor Bender Percepto-Motora

Testes de Percepção Visual Teste de Percepção Visual.

TABELA 3 - Frequência (f) de Relatórios de Avaliação Psicológica que identificam os nomes dos testes.

Pode-se verificar que os Relatórios identificam vários tipos de testes utilizados para avaliação psicológicas da criança encaminhada para CEDM: testes de nível intelectual, de prontidão para alfabetização, de personalidade, de maturidade percepto motora, percepção visual e de maturidade social. Entretanto, os tipos de testes mais freqüentemente mencionados foram de nível intelectual seguidos pelos de prontidão para alfabetização e maturidade percepto-motora. Dentre os testes de nível intelectual, foram mencionados em ordem decrescente de frequência os seguintes: Columbia, Wisc, Goodenough, Stanford-Binet e Raven. Dentre os testes de prontidão para alfabetização foi mencionado com maior frequência o Teste Metropolitano de Prontidão seguido do teste de Eloah Ribeiro Kunz e o APPI. Já para avaliação das outras áreas foi 
mencionado sempre um único teste, ou seja, para personalidade o HTP, para maturidade social a Escola de Vineland, para maturidade percepto-motora o teste Guestáltico Viso Motor de Bender e para percepção visual o teste de Percepção Visual de Frostig.

O quadro 1 mostra os valores de QI constantes diretamente nos Relatórios ou calculados pelos pesquisadores a partir de dados neles contidos referentes à idade mental (IM) e idade cronológica (IC) e sua classificação de acordo com a Organização Mundial de Saúde (OMS).

Observa-se que dos 63 Relatórios de Avaliação Psicológica consultados, $16(25,39 \%)$ contém dados de QI ou dados que permitem seu cálculo. Os valores de QI encontrados variam de 47 a 80, podendo-se notar uma maior concentração entre os valores de 60 e 80 . Em termos da classificação proposta pela OMS, verifica-se nesses 16 relatórios, que oito deles apresentam dados que permitem classificar os alunos como Deficientes Mentais Limiares, sete como Deficientes Mentais Discretos e apenas um como Deficiente Mental Moderado.

\section{Outras análises efetuadas mostram que:}

A) Em 37 relatórios $(58,73 \%)$ há dados referentes a avaliaçāo psicomotora da criança rue ou indicam diretamente a idade viso-motora (exemplo - " A criança apresenta uma maturidade percepto-motora igual a 5 anos e 6 meses"), ou localizam o desenvolvimento psicomotor em relação à idade cronológica (exemplo- "Os Testes psicomotores demonstram desenvolvimento praticamente compativel com a idade") ou ainda definem o desenvolvimento psicomotor da criança como deficitário (exemplos - "Integração visual motora pobre"; "Desenvolvimento motor bastante prejudicado apresentando sérias dificuldades nesta área")

B) Apenas 8 Relatórios $(12,69 \%)$ contém dados relativos à avaliação de personalidade sendo muito variada a forma de apresentação desses dados, aparecendo desde considerações mais sintéticas (do tipo "apresenta perturbaçōes emocionais") até mais extensas e detalhadas focalizando, em uma linguagem bastante técnica, aspectos do relacionamento afetivo-emocional, familiar, social e sexual da criança (conforme alguns trechos aqui mencionados a título de ilustração: "no relacionamento afetivo-emocional mostra-se coartativo e bloqueado, o mesmo se observando em seu comportamento latente... no campo sexual revela problema, sentimento de culpa podendo ser por masturbação, temor de castração, preocupação e policiamento aos impulsos do corpo...").

C) Um único relatório faz referências a exame realizado por outro profissional (exame médico) e em dois Relatórios aparece a indicaçāo feita pelo próprio psicólogo de atendimento psicológico, psicopedagógico e práticas esportivas para a criança e de orientaçăo para os pais.

Paidéia. FFCLRP - USP, Rib. Preto, 3, Ago/Jan, 1993. 


\begin{tabular}{ll}
$52\left(^{*}\right)$ & D.M. Discreta \\
$79\left(^{*}\right)$ & D.M. Limiar \\
$57\left(^{*}\right)$ & D.M. Discreta \\
$68\left(^{* *}\right)$ & D.M. Limiar \\
$66\left(^{*}\right)$ & D.M. Discreta \\
$67\left(^{*}\right)$ & D.M. Discreta \\
$78\left(^{*}\right)$ & D.M. Limiar \\
$80\left(^{*}\right)$ & D.M. Limiar \\
$56\left(^{*}\right)$ & D.M. Discreta \\
$60\left(^{* *}\right)$ & D.M. Discreta \\
$62\left(^{*}\right)$ & D.M. Discreta \\
$70\left(^{*}\right)$ & D.M. Limiar \\
$75\left(^{* *}\right)$ & D.M. Limiar \\
$70\left(^{*}\right)$ & D.M. Limiar \\
$47\left(^{*}\right)$ & D.M. Moderada \\
$80\left(^{*}\right)$ & D.M. Limiar \\
\hline
\end{tabular}

Número total de relatórios $=63$

Número de relatórios que apresentam diretamente dados de QI ou dados qua permitem calculá-lo $=16$

* ) O QI da criança consta no relatório

(**) O QI da criança foi calculado pelos pesquisadores a partir de dados de IM e IC constantes no relatório.

(***) A classificaçăo de acordo com a OMS foi feita pelos próprios pesquisadores.

QUADRO 1 - Apresentação dos valores de QI constantes nos Relatórios ou calculados a partir de dados neles contidos e sua classificação segundo a OMS. 
D) Os Relatórios deixam evidente, quase na sua totalidade, que o encaminhamento da criança para CEDM é feito com base nos resultados da própria avaliação psicológica, não sendo mencionados quaisquer outros motivos como responsáveis pelo encaminhamento.

E) Quanto à indicação com relação à classe que a criança deverá freqüentar, cerca de $57 \%$ dos Relatórios indicam classe especial ou educação especial e são poucos os Relatórios $(1,59 \%)$ indicando pré-primário, classe regular com grupo de apoio e atenção individualizada e classe para crianças com dificuldades de aprendizagem. Entretanto, cerca de $38 \%$ dos Relatórios não contém qualquer indicação quanto ao recurso educacional considerado mais adequado para a criança avaliada.

A tabela 4 mostra a porcentagem de Relatórios que contém algum tipo de orientação ao professor em relação ao seu trabalho junto a criança. Nota-se que 47,62\% dos Relatórios não fornecem qualquer indicaçāo nesse sentido. Nos restantes foram identificados três tipos de orientação ou sugestão para os professores:

\begin{tabular}{|c|c|c|}
\hline Tipo de Orientação ao Professor & $\mathbf{f}$ & $\%$ \\
\hline $\begin{array}{l}\text { Indicação de exercícios e e } \backslash \text { ou atividades } \\
\text { específicas }\end{array}$ & 2 & 3,17 \\
\hline Indicação das áreas deficitárias & 4 & 6,35 \\
\hline $\begin{array}{l}\text { Indicação quanto a atitude e comportamentos } \\
\text { mais gerais do professor }\end{array}$ & 9 & 14,29 \\
\hline $\begin{array}{l}\text { Indicação de exercícios e } \backslash \text { ou atividades } \\
\text { específicas \Indicação quanto a atitude e } \\
\text { comportamentos mais gerais do professor }\end{array}$ & 2 & 3,17 \\
\hline $\begin{array}{l}\text { Indicação das áreas deficitárias } \backslash \text { indicação } \\
\text { quanto a atitudes e comportamentos mais } \\
\text { gerais do professor }\end{array}$ & 16 & 25,40 \\
\hline Nenhuma indicação & 30 & 47,62 \\
\hline
\end{tabular}

TABELA 04 - Freqüência e porcentagem de Relatórios de Avaliação Psicológica que contem algum tipo de orientação ao professor. 
- Indicação de exercícios el ou atividades específicas a serem desenvolvidas junto à criança. Exemplos: "exercícios contidos nos Subsídios e Recursos Didáticos para a Pré-Escola da Secretaria da Educaçāo _ CENP"; "exercícios ao ar livre: respiratórios, de marcha e de equilíbrio"; "exercícios de discriminação de semelhanças e diferenças".

. Indicação das áreas que devem ser trabalhadas sem indicação de exercícios e $\backslash$ ou atividades específicas. Exemplos: "treino da área motora"; "desenvolvimento da área social"; treino de habilidades básicas ".

- Indicação quanto a atitudes e comportamentos mais gerais do professor em relação à criança. Exemplos: "fornecer auxilio individual na excução das tarefas"; "valorizar a criança".

A orientação mais freqüentemente encontrada refere-se a atitudes e comportamentos mais gerais do professor em relação à criança $(42,86 \%$ dos Relatórios) seguida de indicação das áreas deficitárias (31,75\%). Por outro lado, a indicação ao professor de exercícios e $\backslash$ ou atividades específicas a serem desenvolvidas junto a criança aparece em apenas $6,34 \%$ dos Relatórios. E interessante notar que em $28,57 \%$ dos Relatórios foram encontrados dois tipos de indicação, sendo comum a indicação quanto a atitudes e comportamentos mais gerais do professor.

\section{4- DISCUSSÃo.}

Apesar de os dados obtidos nesse trabalho se configurarem como pontos para reflexões e análises e conseqüentemente para posteriores intervençōes nas CEDM, é imprescindível considerar que foram coletados junto a uma amostra reduzida em condiçōes de tempo e local específicos, exigindo assim cuidados na sua generalização. Contudo, os resultados a que se chegou a partir da análise do conteúdo dos Relatórios de Avaliação Psicológica dos alunos de seis CEDM da cidade de Ribeirão Preto, deixam evidente que questōes relativas a avaliação e encaminhamentọ dessas crianças e a própria elaboração dos respectivos relatórios devem ser motivos de preocupação, reflexão e mobilização urgente dos profissionais envolvidos.

Inicialmente pode-se levantar que apesar da ênfase dada na importância de se considerar dados advindos de observações da criança na decisão acerca do tipo de educação que esta deverá receber, a análise dos relatórios de Avaliação Psicológica indica que o encaminhamento das crianças é feito quase na sua totalidade com base nos resultados da própria avaliação o qual se constitui primordialmente da utilização de testes. Conforme já foi citado anteriormente as próprias concepçōes legais sugerem a utilização de testes, uma vez que, para freqüentar CEDM, exige-se a classificação da criança como deficiente mental, grau leve. Não pretendemos de forma alguma sugerir a não utilização de testes na avaliação psicológica das crianças, mas sim ressaltar a importância da utilização concomitante de outras formas de avaliação que possam completar os resultados dos testes e fornecer mais elementos para que o 
Relatório de Avaliação Psicológica apresente ao professor informações que o ajudem no seu trabalho junto ao aluno.

O presente trabalho encontrou $21,25 \%$ de alunos freqüentando CEDM sem possuírem Relatório de Avaliação Psicológica. Isso não parece ser um fato raro, sendo que porcentagem bem maior foi encontrada por Paschoalick (1981) que verificou 61,40\% de crianças matriculadas em CEDM sem avaliaçăo prévia. O reconhecimento de que uma considerável porcentagem de crianças são matriculadas e freqüentam CEDM sem a necessária avaliação psicológica, é indício de não estar sendo integralmente respeitado o critério estabelecido por lei para a admissão da criança em classe especial. Cabe lembrar aindá a inexistência da avaliação educacional, recomendada pelos dispositivos legais e que deve ser realizada antes da avaliação psicológica. Contudo, não foi encontrado neste projeto nenhum caso em que a valiação educacional estivesse compondo a avaliação geral da criança.

Pode-se verificar a variedade de técnicas utilizadas na avaliação de cada criança sugerindo que a escolha dessas técnicas pode estar sendo realizada em funçāo das preferências de cada profissional, ou ainda, da instituição à qual se encontra vinculado, como já havia sido notado por Denari (1984).

É provável que a proposta sistematizada pelo DAE $\backslash S E$ acerca dos conteúdos dos Relatórios 'enha surgido como consequência de constataçōes já feitas, semelhantes às que encontramos no presente estudo e que refletem uma total falta de consenso entre os psicólogos para realizarem as avaliações e relatarem os resultados.

Verificou-se que, dentre os instrumentos de avaliação utilizados, os testes de nível intelectual foram os mais freqüentemente mencionados, aparecendo em $84,12 \%$ dos Relatórios, sendo que em alguns casos esses mesmos testes se constituiram no único instrumento de avaliação da criança. Esse dado parece estar de acordo com as afirmações de Matuszek e Oakland (1979), Palmer (1980), Fields e Kumar (1982) e Schneider e Byrne (1984), de que os escores de inteligência (QI) são muito considerados quando se vai fazer decisōes educacionais, mesmo que nāo sejam suficientes para se julgar a prontidão do aluno.

E interessante notar também que, em somente $11,14 \%$ dos Relatórios a observação clínica e a avaliação do repertório de habilidades da criança foram mencionadas. A pouca utilização dessas técnicas indica que provavelmente grande parte das avaliaçōes possam estar deixando de contribuir no sentido de proporcionar conhecimento acerca da criança a partir de uma forma de avaliação mais direta, independente dos vieses culturais que envolvem os testes.

Observa-se também que os resultados da avaliação específica da área psicomotora são apresentados de forma quantitativa ou normativa, localizando o desenvolvimento psicomotor da criança em relação a idade cronológica ou 
definindo-o como deficitário. Se por um lado, tais resultados podem fornecer informações específicas sobre a criança, por outro podem gerar nos professores expectativas negativas ou concepções pré-estabelecidas, prejudicando o seu trabalho e conseqüentemente o desenvolvimento do aluno.

Supomos que uma descrição mais detalhada acerca das áreas a serem treinadas poderia contribuir no direcionamento do trabalho do professor quanto às dificuldades peculiares de cada criança.

No entanto, pode-se verificar que quase metade dos relatórios não oferecem qualquer orientação ao professor e quando o fazem, apresentam em sua maioria sugestōes gerais ou inespećficas para guiar o seu trabalho junto ao aluno. E provável que as avaliaçōes sejam realizadas de forma precária e que o psicólogo realmente nāo consiga levantar informaçōes suficientes acerca da criança a ponto de se sentir capaz de fazer formulaçōes adequadas e fundamentadas a respeito das necessidades de cada um para posteriores intervenções.

Deve ser destacado também que apenas pequena parte dos Relatórios fornecem dados a respeito da avaliaçāo de personalidade da criança. Contudo, nos que os fornecem aparecem afirmaçōes muitas vezes enfatizando características negativas ou dificuldades da criança e mediante a utilizaçāo de termos técnicos que podem ser totalmente desconhecidos, ou pior, erroneamente interpretados pelos professores.

Todas as indagações levantadas acerca da forma pela qual a avaliação psicológica vem sendo realizada, viabilizam o questionamento acerca das reais justificativas dos encaminhamentos já realizados. Esse questionamento estretanto não significa uma atitude negativa quanto ao reconhecimento de casos que indubitavelmente exigem cuidados especiais de educação. $O$ que se põe em dúvida é se realmente estão sendo considerados os vários fatores que poderiam ser responsáveis pelo fracasso escolar de umia criança. Isso equivale a dizer por exemplo que se o motivo apresentado para o encaminhamento é dificuldade de acompanhar o ensino regular, dever-se-ia investigar quais as razões que estão contribuindo para a criança fracassar especulando tanto aquelas ligadas às características da criança quanto as do sistema educacional ao qual a criança está submetida. Essa investigação poderia possibilitar a descoberta de fatores associados ao fracasso da criança, permitindo até que sejam feitas alteraçōes nas condições de aprendizagem prevendo muitas vezes encaminhamento indevido para classe especial. Uma vez estabelecida a classe regular como fator desencadeante do processo de encaminhamento para CEDM, supomos que a melhoria de suas condições de ensino contribua na prevenção de futuros encaminhamentos de muitos alunos que apresentam problemas de comportamento e $\backslash$ ou aprendizagem. Por outro lado, a própria facilidade de se criar classes especiais e o fato de o professor ter esse recurso disponível, pode desestimulá-lo a procurar resolver os problemas das crianças na classe regular. Além disso, pode-se supor que o próprio professor, por falta de tempo disponível

Paidéia, FFCLRP - USP, Rib. Preto, 3, Ago/Jan, 1993. 
visto que trabalha com uma classe de 40 a 50 alunos, ou ainda por não estar devidamente preparado tendo que aprovar um número cada vez maior de alunos, procure se livrar da responsabilidade de ter que responder pela aprendizagem de determinadas crianças, atribuindo-lhes assim a necessidade de freqüentarem classe especial.

Dessa forma, a decisão de quem deva ser cliente de classe especial poderia talvez ser mais acertada se efetuada por uma equipe multidisciplinar, como é exigido pelos dispositivos legais. Além disso, poderia ser recomendável um trabalho de observação e de avaliação do desempenho do aluno com suspeita de problemas de aprendizagem, incluindo a participação do professor especializado nesse processo, que via de regra, recebe a criança, sem ter tido a oportunidade de participar em relação às decisōes educacionais sobre a criança. O processo inverso também poderia ser aconselhável, ou seja, a equipe trabalhando no sentido de auxiliar o professor especializado de forma que fosse viável preparar a criança para a aprendizagem em classe regular.

Essas e outras sugestōes que poderiam ser formuladas com o objetivo de melhorar as condiçōes de aprendizagem dos alunos devem ser analisadas cuidadosamente, procurando-se adequar as necessidades com as condiçōes de realização dessas mudanças. Finalmente, acreditamos que o trabalho permite a constatação de sérios problemas envolvidos no processo de decisão do possível cliente de CEDM e consideramos urgente a mobilização dos profissionais da área para que, em conjunto, reflitam sobre possíveis propostas de solução.

\section{REFERENCIAS BIBLIOGRÁFICAS}

BAGNATO, S.J. The efficacy of diagnostic of reports as individualized guides to prescriptive goal planning. Exceptional Children, 46 (7): 554-557, 1980.

DENARI, F.E. Análise de critérios e procedimentos para a composição de clientela de classes especiais para deficientes mentais educáveis. Dissertaçāo de Mestrado defendida junto ao Programa de Mestrado em Educação Especial, Centro de Educação e Ciências Humanas da UFSCAr, São Carlos, 1984.

DIÁRIO OFICIAL dO ESTAdO dE SĀo PAULO . Instrução DAE\SP.p. 13, 24 de dezembro 1986.

FIELDS, J.P. \& KUMAR, V.K. How teachers use the group I.Q. test scores. Journal of School Psychology, 20(1): 32-38, 1982

HOLLAND, R.P. An analysis of the decision making processes in special education. Exceptional Children, 46(7): 551-553, 1980. 
ISNARD, L.B.; NAIME, A.K.; PENAZZO, A.A.; FARIA, M.C.P.; MODENESI, M.C.C.; FRANCISCO, M.C.; MACHADO, M.C.R.; CARONI, R. A. L. Subsídios para a implantação de programas de educação especial no sistema educacional do Estado de São Paulo, Secretaria da Educação, Coordenadoria de Estudos, Normas Pedagógicas, São Paulo, 1977.

KNOFF, H.M. Effect of diagnostic information on special education placement decisions. Exceptional Children, 49(5): 440-444, 1983.

MATUSZEK, P. \& OAKLAND, T. Factors influencing teachers' and psychologist's recommendations regarding special class placement. Journal of School Psychology, 17(2): 116-125, 1979.

PALMER, DJ. Factors to be considered in placing handicapped children in regular classes. Journal of School Psychology, 18(2): 163-171, 1980.

PASCHOALICK, W. CICCONE. Análise do processo de encaminhamento de crianças às classes especiais para deficientes mentais desenvolvido nas escolas de $1^{2}$ grau da delegacia de ensino de Marilia. Dissertação de mestrado defendida na PUC de São Paulo, São Paulo, 1981.

SCHNEIDER, B.H. \& BYRNE, B.M. Predictors of sucessful transition from self-contained special education to regular class settings. Psychology in the Schools, 21: 375-380, 1984.

\section{ABSTRACT}

The data contained in the Psychological Evaluation Reports from the special classes for mental deficient children were analyzed in this work according the schedule proposed in the Intrução DAE \SE, published in the Diario Oficial do Estado de São Paulo (1986). Others analyses were added considering the researchers' interest. It was possible verify that the Reports were available in $79 \%$ of the students. The analyse of the data demonstrated that there was no agreement pattern between the psychologists in performing the evaluation as were as in presenting the results. Different kinds of techniques and tests were used and most of them were related to intellectual level evaluation. Among the Reports analyzed some of them presents the IQ values (25\%), and most of them do not mention the kind of class to be attended by the child (38\%) neither contain any orientation in order to help the teacher towards his work with the child (47\%).

Palavras - Chave: - Educação Especial; Deficiência Mental; Avaliação Psicológica; Classe Especial.

Key-words: Special Education; Mental Deficiency; Psychological Evaluation; Special Class. 